dienen m.i. deze eis van het maatschappelijk verkeer voor ogen te houden, terwijl het naar mijn mening aanbeveling zou verdienen indien de besturen van de effectenbeurzen in dit opzicht bepaalde minimum-eisen zouden stellen aan de publicaties der ondernemingen, welker aandelen of obligaties ter beurze genoteerd worden, zulks min of meer in navolging van het voortreffelijk werk dat de Securities and Exchange Committee (SEC) in de Verenigde Staten verricht.

Ik wil geenszins betogen, dat wij bij de publicaties der samenstelling van de uitkomsten zóver moeten gaan als in de Verenigde Staten (met name de openbaarmaking der verkopen zal in een klein land als het onze op veel tegenstand stuiten), maar een verbetering in dit opzicht is $m . i$. bij ons te lande strikt noodzakelijk.

Melbourne, 6 December 1947.

\title{
VERBIJZONDERING IN DE UITOEFENING VAN HET ACCOUN- TANTSBEROEP?
}

\author{
door Th. M. van Erp
}

In zijn opstel over het bovenstaande onderwerp nodigt Prof. H. J. v. d. Schroeff de vakgenoten bij herhaling uit tot discussie over dit zo actuele onderwerp; aan deze uitnodiging wil ik gaarne gevolg geven.

Prof. v. d. Schroeff geeft over zijn onderwerp een vrij uitvoerige beschouwing, waarbij de elementen hiervan stuk voor stuk worden geanalyseerd. Bij de lezing van deze analyse is het mij telkens weer opgevallen, dat de hooggeleerde schrijver zich heeft beperkt tot een zuiver theoretische redenering, daar slechts éénmaal de aandacht wordt gevestigd op de omstandigheden van het economische leven na de tweede wereldoorlog.

De vraag kan worden gesteld of deze methode van behandeling van een actueel onderwerp de juiste is. Natuurlijk heeft elke methode zijn voordelen en nadelen, doch, naar het mij wil voorkomen, overwegen in dit geval de laatste. De voordelen zijn die van elke theoretische beschouwing: een scherp principiëel inzicht in de verschillende aspecten van een vraagstuk. Het gaat mij echter vooral om de nadelen en daaraan zou ik hier derhalve wat meer aandacht willen besteden.

Prof. v. d. Schroeff gaat in zijn artikel uit van een door hem niet genoemd axioma. Zijn beschouwingen zijn namelijk ontleend aan de economische verhoudingen, waarin het accountantsberoep zich heeft ontwikkeld en in deze verhoudingen was als hoofdkenmerk waar te nemen: de vrije concurrentie.

Reeds vóór de oorlog begon het beginsel van ,free enterprise", althans in Europa, te wankelen, doch de oorlog heeft deze tendenz aanmerkelijk versterkt. De vrije concurrentie is in West Europa verleden tijd geworden. De toekomst zal leren of er sprake is van voltooid verleden tijd.

In dit licht bezien kan de vraag worden gesteld of een angstvallige geheimhouding van wat Prof. v. d. Schroeff noemt: ,Bedrijfsgeheimen, ..... waarop de voorsprongspremie van het bedrijf is gebaseerd" wel in overeenstemming is met de eisen, die thans aan het bedrijfsleven worden gesteld.

$Z_{\text {ijn }}$ er niet talloze gelijksoortige. maar niet met elkander concurrerende bedrijven, die gezamenlijk efficienter kunnen worden door van elkaar methoden over te nemen?

Zouden de bedriiven de noodzaak van geheimhouding ook zelf voelen, 
het zou er met onze bedrijís-economische literatuur slecht voorstaan. Zowel de bedrijfshuishoudkunde als de accountancy zijn ontstaan en hebben zich ontwikkeld door een studie van de praktijk en vele monografieën omtrent bepaalde bedrijfstakken hebben het licht gezien en hebben degenen, die zich met een theoretische studie bezighielden, een inzicht verschaft in de praktijk der grote bedrijven. De schrijvers van al deze boeken en brochures openbaren in de gedachtengang van Prof. v. d. Schroeff, ,bedrijfsgeheimen", want de concurrenten kunnen aan deze boeken toch steeds wel het nodige material ontlenen om hun eigen bedrijf efficiënter te maken.

Welk een grote betekenis voor het administratieve beheer (om op ons eigen terrein te blijven) hebben de publicaties gehad van leidende functionarissen bij Philips en de Nederlandse Spoorwegen. De studies, die van deze kant zijn gekomen, zijn uiteraard algemeen en in zekere zin theoretisch, maar zij zijn ontstaan in het laboratorium van de praktijk bij twee grote Nederlandse bedrijven en het lijkt mij toe, dat er een woord van waardering op zijn plaats is voor de openhartigheid, waarmede deze instellingen hun interne problemen in vele publicaties aan de buitenwereld hebben blootgelegd.

In dit verband kan bijv. nog worden gewezen op de systematische uitwisseling van administratieve ervaringen tussen vele grote bedrijven in de Studiekring voor Moderne Kantoororganisatie (Stumoka), waarbij over en weer bezoeken worden afgestoken en men er een eer in stelt zijn ervaringen aan anderen ter beschikking te stellen.

In het licht van deze feiten kan nu de volgende vraag worden gesteld: Welke bezwaren zijn er tegen, wanneer de accountant zijn specifieke deskundigheid van een bepaalde bedrijfstak benut om de bedrijven stuk voor stuk een grotere efficiency te geven. Het betoog, dat hiermede de geheimhoudingsplicht op ongeoorloofde wijze wordt geschonden, lijkt mij te stammen uit een periode, die als een door de 2 e wereldoorlog volledig afgesloten tijdperk kan worden beschouwd.

Ik kan mij voorstellen, dat een chocoladefabriek de samenstelling van zijn product angstvallig geheim houdt. Daarin toch ligt het speciale ken merk van het bedrijf, maar waarom zouden twee chocoladefabrieken elkaar niet iets kunnen leren omtrent de gang van het productieproces, de methode van administreren en in het algemeen alle technische en administratieve aangelegenheden? Deze uitwisselingen kunnen het bedrijfsleven als geheel slechts ten goede komen en, zie ik de gangbare mening van de Nederlandse bedrijfsleiders goed, dan onderschrijven zij dit standpunt. Maar, zo vraag ik, is het dan nodig of wenselijk, dat de accountant op het "ouderwetse" geheimhoudingsstandpunt blijft staan? Welk bezwaar is er tegen, wanneer hij in chocoladefabriek $A$ een handige methode van grondstoffenverantwoording ziet deze introduceert bij chocoladefabriek B. En omgekeerd, bij de administratie van het productieproces in fabriek B goede ideeën tegenkomt en deze toepast in de administratie van fabriek A? Geheimhouding zou hier slechts in strijd zijn met het algemene belang.

Het zal na het bovenstaande duidelijk zijn, dat de conclusie van Prof. v. d. Schroeff, dat ,het vraagstuk van de specialisatie op de categorieën van bedrijven ......... geen levend vraagstuk" is, door mij geenszins wordt onderschreven. $\mathrm{Ik}$ meen integendeel, dat het springlevend is.

De accountant kan door zijn werk bij gelijksoortige bedrijven sneller en vooral deskundiger zijn taak uitvoeren en juist daaraan ontleent hij zijn waarde als adviseur van de leiding van het bedrijf. Ik kom op dit punt nog nader terug. 
Het bovenstaande houdt geenszins in, dat ik blind ben voor bepaalde aan de specialisatie verbonden gevaren. Hiervoor moge kortheidshalve worden verwezen naar mijn artikel hieromtrent in het Juni nummer 1946 van dit maandblad.

Werd in het voorgaande de specialisatie in de uitoefening van het accountantsberoep vooral van accountants-standpunt bezien, een andere vraag is, wat de geadviseerden denken van de diensten, die hen door accountants worden bewezen. Dit punt is zeker niet van belang ontbloot, want de accountant moge op grond van zijn opvattingen omtrent de beroepsuitoefening ten aanzien van velerlei aspecten een eigen mening hebben, hij blijft echter een onderdeel van het productie-proces, die zijn waarde slechts bewijst, doordat het maatschappelijk verkeer van zijn diensten gebruik wil maken. De vraag, die ik daarom zou willen stellen luidt: Onderschrijft het bedrijfsleven thans de mening van Prof. v. d. Schroeff, dat de (algemene) accountant de deskundige is op het gebied van de administratie en de bedrijfs-economie?

Herhaaldelijk beluisterde ik de opmerking, dat de accountants voor talrijke vraagstukken niet de aangewezen raadslieden zijn, juist omdat zij onvoldoende gespecialiseerde kennis hebben of - ondanks het feit, dat zij als controlerend accountant werkzaam zijn - de specifieke moeilijkheden van dat bedrijf onvoldoende beheersen. De klacht luidde, dat de accountants-adviezen te vaag, te algemeen en onvoldoende deskundig zijn.

Particuliere informaties zijn gevaarlijk, omdat men nooit weet in hoeverre zij kenmerkend zijn voor het geheel. Er zijn echter aanwijzingen, die deze mening bevestigen en hiervan wil ik er, zonder daarbij te bogen op volledigheid, een aantal noemen. Het zal daarbij blijken, dat het hierbij steeds gaat om de adviserende functie van de accountant en dat zijn deskundigheid in de contrôle-functie nooit wordt aangetast:

a. Grote bedrijven vragen in het algemeen geen adviezen aan accountants, maar hebben voor het terrein, dat geacht wordt door de accoun tant te worden bestreken, eigen gespecialiseerde krachten in dienst. Het kosten-element kan hier gevoeglijk worden uitgeschakeld, omdat, zeker in een groot bedrijf, voor een werkelijk goed advies (terecht) niet op de kosten wordt gekeken. Kunnen de specialisten in het be drijf een probleem niet ten volle aan, dan wenden zij zich niet tot een accountant, maar tot een speciaal adviesbureau.

b. Alom is waar te nemen, dat zowel door de overheid als in bepaalde sectoren van het bedrijfsleven, gespecialiseerde accountantsdiensten in het leven worden geroepen. Zelfs is binnen de overheidsaccountantsdiensten weer een zekere specialisatie waar te nemen. Dit wijst onmiskenbaar op een bestaande behoefte, die niet uitsluitend uit kostenoverwegingen is te verklaren. Een goed georganiseerd accountantskantoor zal, wat de prijs betreft, vermoedelijk wel kunnen concurreren met een gespecialiseerde dienst en het wil mij dan ook voorkomen, dat de specialisatie voornamelijk is gegrond op de overweging, dat de adviezen van de algemene accountants Bnvoldoende zijn voor de behoeften, die het bedrijfsleven thans (d.w.z. in onze gecompliceerde en van boven geleide samenleving) heeft. Dat deze gespecialiseerde accountantsdiensten uit accountants-oogpunt bepaalde gevaarlijke aspecten hebben, ben ik mij bewust. Ook hiervoor moge ik naar mijn bovenaangehaald artikel verwijzen. 
c. De adviesbureaux op het gebied van bedrijfseconomie en administratieftechnische onderwerpen nemen toe in aantal en omvang, waaruit kan worden geconcludeerd, dat zij een voorspoedig bestaan leiden. Ook dit wijst weer op een behoefte van het bedrijfsleven, want kon aan de vragen, die door het bedrijfsleven worden gesteld, door de gevestigde accountants worden voldaan, dan ware het logisch, dat de bedrijfsleiders zich tot hen zouden wenden.

d. Er zijn reeds accountantskantoren, die in hun organisatie specialisten op verschillend gebied hebben opgenomen, bijv. voor budgettering, mechanisatie van kantoorarbeid e.d. Het zijn zeker niet de kantoren met een matige wetenschappelijke opvatting van het werk, die hiertoe over gaan. Integendeel, de leiders van deze kantoren voelen hun tekortkomingen en trachten deze door het aantrekken van specialisten aan te vullen.

Men kan de hier geschetste ontwikkeling betreuren; het is evenwel de harde werkelijkheid en de accountants kunnen er niet mee volstaan, deze werkelijkheid af te wijzen als op een zo duidelijke wijze blijkt, dat de accountant door de geadviseerden niet (meer) als de deskundige wordt gezien.

Het artikel van Prof. v. d. Schroeff geeft een (verspreide) opsomming van de bijzondere deskundigheden, die hij aan de accountant in verband met zijn adviserende functie toeschrijft. Het is een indrukwekkende lijst en het lijkt mij nuttig al deze deskundigheden eens achter elkaar op te schrijven.

,Alle voorkomende administratie- en organisatie-technieken en van technische hulpmiddelen, bij welke laatste te denken valt aan de hulpmiddelen van de gemechaniseerde administratie".

,De vraagstukken in de meest ruime zin ........ met betrekking tot de kosten- en efficientiebeoordeling, de bepaling van de kostprijs, de prijsstelling, de waardebepaling en winstberekening, de financiering."

.Ditzelfde geldt - eveneens zonder beperking - voor het gebied van de administratieve organisatie in zijn volle omvang".

"De structuur van de arbeidsverdeling, de organisatie van de leiding en de contrôle, de inkoop- en verkoop-organisatie, beoordeling van de voorraadvorming, planning, budgettering om enige te noemen. Voor andere vraagstukken als markt-analyse, mathematisch-statistische analyse is wellicht in de naaste toekomst een taak voor de accountant weggelegd".

Kan nu werkelijk worden betoogd, dat de accountants in het huidige stadium van ontwikkeling van de bedrijfs-economie en de accountancy al deze moeilijke vraagstukken op verantwoorde en deskundige wijze kunnen behandelen, in het bijzonder, wanneer het om grote bedrijven gaat? En is het dan wonder, dat over de ",deskundige" accountantsadviezen door de bedrijfsleiders wel eens wat medelijdend wordt geglimlacht? Het aanzien van de accountants-stand is hiermede geenszins gebaat en het probleem, waarvoor wij staan, is, dat wij niet op straktheoretische gronden onze ,algemeenheid" mogen blijven propageren, maar ons ernstig moeten bezinnen op de eisen, die het maatschappelijk verkeer in 1947 wan de accountant stelt.

Waar Prof. v. d. Schroeff er mede volstond het vraagstuk der differentiatie aan de orde te stellen en specialisatie volledig van de hand te wijzen, ben ik verder gegaan en heb ik de specialisatie niet zonder meer afgewezen en de noodzaak ener differentiatie betoogd. Specialisatie en differentiatie sluiten elkander trouwens niet uit. Er zijn bedrijfstakken, 
waar de bedrijfseconomische en administratief-technische problemen niet van een zodanige gecompliceerdheid en omvang zijn, dat de accountant deze niet zou kunnen beheersen; er kan hier bijv. worden gedacht aan handelszaken, kleinindustrie e.d. Specialisatie lijkt hier in elk geval te overwegen. Bij de grootindustrie, grote verkeersbedrijven, e.d. komt de differentiatie meer als wenselijkheid naar voren. De praktijk is echter zo veelzijdig geschakeerd, dat vaste regels hier zeker niet kunnen worden gegeven.

Het bovenstaande is niet volledig, omdat wordt volstaan met critiek en het min of meer vaag aangeven van een door mij wenselijk geachie richting van ontwikkeling in de uitoefening van het accountantsberoep. Dit vraagstuk moet verder worden uitgewerkt en doordacht; ik hoop, dat er lezers zijn, die voldoende specifieke deskundigheid en ook tijd bezitten om deze studie te kunnen voltooien. Wellicht kan Prof, v. d. Schroeff́ de gelegenheid vinden zijn mening nader te preciseren.

\section{Naschrift.}

Het is mij bij lezing van de beschouwing van de heer Van Erp opgevallen, hoe de keuze van een enkel woord een zekere kleur aan een betoog kan geven. Ik doel hierbij op de uitdrukking van genoemde schrijver, dat ik ,angstvallig" het bewaren van de geheimen van het bedrijf voor zou staan. Laat mij allereerst de heer Van Erp geruststellen; elke angstvalligheid ten deze is mij vreemd. Dat hij zulks bij mij veronderstelt, is een gevolg van het feit, dat hij de bedoeling van hetgeen ik in mijn artikel heb willen betogen, heeft misgevat.

Ik wil vooropstellen, dat ik niet minder waardering heb voor de onderlinge uitwisseling van gegevens van bedrijven dan de heer Van Erp. De woorden, die Prof. Goudriaan nu al weer jaren geleden uitsprak voor de propagering van de gedachte van bedrijfsstudiegroepen, kan ik geheel tot de mijne maken. I $\mathrm{k}$ zie in de uitwisseling van ervaringen een voordeel voor alle bedrijven, die van dergelijke bedrijfsstudiegroepen deel uitmaken, niet het minst voor het bedrijf, dat mededelingen doet en dat thans in de gelegenheid is de opgedane ervaring aan die van anderen te toetsen.

Dezelfde waardering heb ik voor publicaties, waarin leidende func tionarissen van bedrijven hun kennis omtrent het bedrijfsleven hebben neergelegd. Maar dit alles staat buiten de zaak, waar het ten deze om gaat.

Het kan de heer Van $E_{r p}$ geen ernst zijn, indien hij schrijft, dat ik zou menen, dat in de bovenbedoelde onderling uitgewisselde of gepubliceerde gegevens ,bedrijfsgeheimen" zouden worden openbaard. ledereen toch weet, dat de openhartigheid in de uitwisseling van gegevens en ervaring tussen de bedrijven niet zo ver gaat, dat daarbij de features worden prijsgegeven, welke voor de bedrijfsvoering van vitale betekenis worden geacht en waarvan de winst en in het bizonder de voorsprongspremie van het bedrijf afhankelijk is. Ik denk daarbij in het geheel niet aan mededelingen, welke de inrichting van de administratie betreffen, die - hoe belangrijk op zich zelf ook - geheel in het niet vallen bij de punten van de wezenlijke bedrijfsvoering als de inkooppolitiek, de productie-methode, de door het bedrijf gevolgde prijs - en verkooppolitiek om slechts enkele voorbeelden te noemen. De bedenking, die ik tegen de bedrijfsgewijze verbizondering in de beroepsuitoefening van de openbaar 
accountant heb geuit, ligt niet in de door de specialisatie verkregen meerdere kennis van dat administratieve apparaat (alleen een voordeel van de specialisatie!), maar in de omstandigheid, dat door de voortdurende aanraking met steeds eenzelfde categorie van bedrijven de accountant een zo grote wetenschap verwerft omtrent de door ieder van deze bedrijven gevoerde politiek, dat de geheimhouding in de beroepsuitoefening bij onderling concurrende bedrijven tot een objectieve onmogelijkheid wordt. De door mij gemaakte bedenking komt niet voort uit, gelijk de heer Van Erp het heeft willen noemen, een ouderwets geheimhoudingsstandpunt, maar uit het inzicht, dat elke anomalie ten deze niet meer en niet minder dan een aantasting betekent van een van de wortels van het accountantsberoep.

Het bedrijf, dat van de diensten van de openbaar accountant gebruik maakt, doet dat in het vertrouwen, dat de gegevens, die voor het bedrijf van wezenlijke betekenis zijn, onder zijn geheimhoudingsplicht worden bewaard. Dit geldt niet alleen voor de accountant, maar voor iedere deskundige, die in zijn beroepsarbeid bekendheid verkrijgt met vertrouwensaangelegenheden van het bedrijf. Wat hier gezegd is, geldt inzonderheid met betrekking tot de wetenschap van al die zaken, waarop de voorsprongspremie van het bedrijf steunt. Mijn veroordeling van de specialisatie berust uitsluitend op de moeilijkheden, welke met het oog daarop in de beroepsuitoefening van de openbare accountant worden geschapen. De voorbeelden door de heer Van Erp aangehaald gaan geheel langs het door mij gegeven betoog heen.

Over het tweede gedeelte van het artikel van de inzender wil ik kort zijn. Ik moet alleen mijn verwondering er over uitspreken, als de heer Van Erp mijn woorden op die wijze interpreteert, dat ik de ,algemeenheid" in de beroepsuitoefening zou propageren. Als de schrijver zegt, dat het nodig is ons ernstig te bezinnen op de eisen, die het maatschappelijk verkeer in 1947 aan de accountant stelt, dan heb ik niet anders gewild en daarom het voor het accountantsberoep brandende vraagstuk van de verbizondering - juist om aan de bezwaren van de ,algemeenheid" te ontkomen! - aan de orde gesteld. Moge een betoog op straktheoretische gronden bij de heer Van Erp geen instemming vinden, ik heb een analyse van de zich daarbij voordoende vraagstukken willen geven, om de beoordeling vanuit pragmatisch standpunt aan de practische beoefenaren van het vak over te laten. Ook deze werkverdeling was derhalve een differentiatie. In hoeverre deze differentiatie doelmatig is, laat $i k$ aan het oordeel van de lezer over.

H. J. v. d. S.

\title{
OPMERKINGEN NAAR AANLEIDING VAN HET ARTIKEL OVER MOGELIJKHEDEN EN WENSELIJKHEDEN VAN EEN VERBIZON. DERING IN DE UITOEFENING VAN HET ACCOUNTANTSBEROEP
}

\author{
door Drs. E. J. Flipse
}

Het artikel van Prof. Dr. H. J. v. d. Schroeff in de October-aflevering van dit jaar inzake de verbijzondering in de uitoefening van het accountantsberoep had mijn bijzondere belangstelling.

Aangezien ik zelf deel uitmaak van de Commissie voor de Beroepsontwikkeling, welke door het Bestuur van het N.I.v.A. werd ingesteld, acht ik dit Maandblad echter niet de plaats om de eventuele verschillen van inzicht met hem te behandelen. 